\title{
The effect of velocity on the dispersion of pollutants in a hypothetical arctic open-pit mine
}

\author{
A. Choudhury ${ }^{1} \&$ S. Bandopadhyay ${ }^{2}$ \\ ${ }^{1}$ Mining Engineering Department, Montana Tech of the University, USA \\ ${ }^{2}$ Department of Mining and Geological Engineering, \\ University of Alaska Fairbanks, USA
}

\begin{abstract}
Deep open-pit mines are becoming increasingly common in the highly mineralized arctic and sub-arctic regions. Air inversion is a frequent occurrence in these regions, and is exacerbated by the natural topography of an open-pit mine. Due to such inversions, the air quality in open-pit mines deteriorates very rapidly. Transport of gaseous pollutants under arctic air inversion is complex and involves an interaction between flow, thermal and convective transport systems. This paper discusses the construction and validation of a three-dimensional model that simulate the flow of air and the transport of gaseous contaminants in an arctic open-pit mine and the effect of low influent velocity and large gust velocities on the contaminants profiles in the mine. It was found that while higher velocities may remove contaminants from the pit bottom, they may not remove the contaminants from the pit entirely, necessitating artificial mitigation measures Keywords: open pit mine, pollution transport, air inversion, CFD.
\end{abstract}

\section{Introduction}

The highly mineralized arctic and subarctic regions present some of the most hazardous mining conditions in the world. In addition to dealing with the challenges of permafrost and cold temperatures, open-pit mines in these regions increasingly encounter air inversion as an environmental hazard. Air inversion is a form of fluid inversion that occurs not only in cold climates but also in temperate zones and over large areas such as cities (Dubai and London for example). In the Arctic, however, inversions are known to be particularly severe. 
Air inversion occurs when the natural vertical convection of air from near the earth's surface to higher altitudes is interrupted. In normal, un-inverted conditions, solar radiation transmits heat to the earth's surface via shortwave radiation. A part of this incident radiation is absorbed or transmitted away through the layers of soil, but a large portion of incident radiation is reradiated back to the air mass immediately overlying the surface via longwave radiation. This layer of air heats and rises to higher altitudes, while air from higher altitudes sinks to the surface to fill the vacuum. Continuing this cycle creates the natural vertical convection that is essential for diluting polluted air and removing it from near the surface. However, in arctic or subarctic areas, as well as in valley or trough-shaped topographies in other parts of the world, solar radiation sufficient to initiate and maintain such convective currents often does not impinge on the ground. With convection current interrupted, pollution generated at the earth's surface, whether natural or anthropogenic, is not diluted or transported away, resulting in build-up of pollution and violation of air quality standards. Open-pit mines in the Arctic are particularly vulnerable to this problem because of cold temperatures during most of the year, lack of sufficient solar radiation, and trough-shaped topographies that characterize the ore extraction process.

The aim of this research was to mathematically model the transport and distribution of gaseous pollutants in arctic open-pit mines. A mathematical model of the mine was first created in the $\mathrm{COMSOL}^{\circledR}$ environment. This model consisted of a hypothetical mine geometry that closely represented the geometry of an actual open pit in the Arctic. The model has three primary physical systems to simulate the movement of air and gaseous pollutants within its space: (1) Navier-Stokes equations, simulating flow of air in the model space; (2) convection-conduction equations, simulating thermal interaction between the air mass and the sources of heat in the model space, including the reradiated heat from the surface or the waste heat from working equipment; and (3) convection-diffusion equations, simulating the transport of the gaseous pollutant mass under the influence of airflow.

This model was first validated against data collected from the arctic open-pit mine to which the model geometry conforms. For validation purposes, historical data from the mine were collected for 2004-2005. The model geometry conforms to the mine geometry from that period. Once the model was validated, several influent velocities were input into the model, and their effects on the distribution of gaseous pollutants were examined.

\section{Brief review of available literature}

Literature on the problem of airflow in open-pit mines, particularly with respect to airflow and pollutant dispersion under an inversion cap, is scant. Most of the work has been done in the former Soviet Union.

Since the model is based on an open-pit mine located near Fairbanks, Alaska, and the city of Fairbanks experiences serious inversion problems during winter, it is informative to begin by looking at the nature of the inversion occurring within the city limits. Holty [1] noted that during winter in Fairbanks, particularly under inverted caps of air, $\mathrm{CO}$ and particulate concentrations in the breathable layers of 
air exceeded the (then) EPA standard by as much as five times. He also noted that lead aerosols have a much longer residence time in such cold air than is normally seen. It can be concluded from his investigation that in arctic and subarctic areas, inverted air columns contribute significantly to quality of air and pollution characteristics.

Hartmann and Wendler [2] analysed 47 years of radiosonde inversion data from the city of Fairbanks, and observed a decrease of $212 \mathrm{~m}$ in the mean inversion depth. They also observed an increase of $0.7^{\circ} \mathrm{C} / 100 \mathrm{~m}$ in the mean temperature gradient of the inversion along its altitude. The trends identified by them possibly lead to the conclusion that since the depth of inversion is decreasing and the temperature gradient along that depth from the surface upward is increasing, the difference in temperature between the surface and the top of the inversion layer remains constant.

In order to understand the behaviour of gaseous pollutants within the pit (as the pollutants are transported primarily by advection), it is imperative to understand the characteristics of airflow within an open pit. Most of the work done in this area has been in the former Soviet Union.

Belousov [3] noted that because the air above the pit cools slower than the air above the ground at the same altitude, a resultant horizontal flow of air toward the pit takes place. Belousov also noted that, in such cases, the air above the pit rises due to the standard adiabatic process. However, as in cold climates, air in the lower parts of the pit lacks sufficient energy to participate in such processes, leaving the pollutants generated in that layer stagnant. In an earlier paper [4], Belousov states that the topography of land around the mine may increase the effective depth of the mine, thus hindering the flow of air into the pit and impeding the removal of contaminants. Belousov $[4,5]$ considers the natural expansion angle (around $15^{\circ}$ ) that propels the air within the deeper reaches of the pit to be an important factor in pit ventilation. Upon constructing a scaled model of an in situ mine in China, Peng and $\mathrm{Lu} \mathrm{[6]}$ found that the expansion angle is a function of the depth of the pit. All the efforts just referenced assume that wind flow in the mine is turbulent. The natural expansion angle that directs airflow into the pit may not be viable if the assumption of turbulence is removed.

Fomin [7] investigated the characteristics of airflow in a pit at a more fundamental level. He assumed no external airflow - that the only flow within the pit results from the addition of heat from the walls of the mine. The model used by Fomin predicted an upwelling of air at the center of the pit (chimney effect) so that the contaminants generated in the pit would be taken up by advection and transported out of the pit. However, a constant Grashof number imposed on the entirety of the model space may give more impetus to the chimney effect than is realistic, thus tilting the model outcome in favour of thermal interactions.

Aloyan et al. [8] proposed that local mass and energy balances in addition to planetary forces like the Coriolis Effect have a significant influence on the flow of air over large areas such as open pits. With the inclusion of external heat sources and geometric approximations for irregular mine geometries, it was found that several distinct zones may exist in the flow regime. Turbulent mixing contributes 
significantly to the reduction of pollutant concentrations in the deeper areas of the pit.

Various solutions have been suggested to the problem of stagnant contaminants in open pits. Baklanov and Rigina [9] investigated the possibility of employing cascade ventilation to transport polluted air out of the deeper reaches of the mine. In spite of high power consumption, this method was found ineffective. Belousov [5] advocates the installation of wind vanes (simulated on scaled models in wind tunnels), which he claims can ventilate most of the pit by direct ventilation. This method, however, depends on a constant flow of wind from an appropriate direction. Belousov [3] suggests that by establishing a temperature gradient of 5$10^{\circ} \mathrm{C}$ between the centre and sides of the pit, the natural breeze circulation in the pit can be reinforced, and contaminants can be mixed and remediated. The energy required to establish such a gradient in large open-pit mines in cold regions, however, might be prohibitive.

In recent years, some papers e.g., Collingwood et al. [10] have examined this problem from both $2 \mathrm{D}$ and $3 \mathrm{D}$ perspectives. The work presented here predates and lays the foundation for many of those works.

Most of the models reviewed here have assumed that the flow regime is turbulent. The primary point of departure for this study is that no such assumption has been instituted in the model space, thus leaving the model space to behave according to the requirements of governing physical processes.

\section{Collected data}

The data collected for the model were primarily of three categories: (1) atmospheric data from the area around the open pit, including wind velocity, pressure, temperature, and solar radiation data; (2) exhaust and waste heat data from the working equipment in the mine; and (3) information regarding the behaviour of air over a large range of temperature, including specific heat and conductivity. Since the selected mine does not have a viable weather station, most of the atmospheric data were collected from a NOAA weather station located close to the mine. The data for the production equipment, however, were obtained from the mine.

Production equipment data were supplied by the mine management. This data mainly pertain to fuel consumption of engines in the equipment and the equipment's tailpipe exhaust characteristics. Assuming that a standard of $60 \%$ of the calorific value of fuel is lost as waste heat, the exhaust heat for the equipment can be calculated from fuel consumption. Engine emission characteristics under various loads have been given by Shah et al. [11], and appropriate data from their results were considered.

\section{Construction and validation of a 3D model}

A 3D model was constructed in the $\mathrm{COMSOL}^{\circledR}$ environment. Figure 1 shows an isometric representation of the model. 


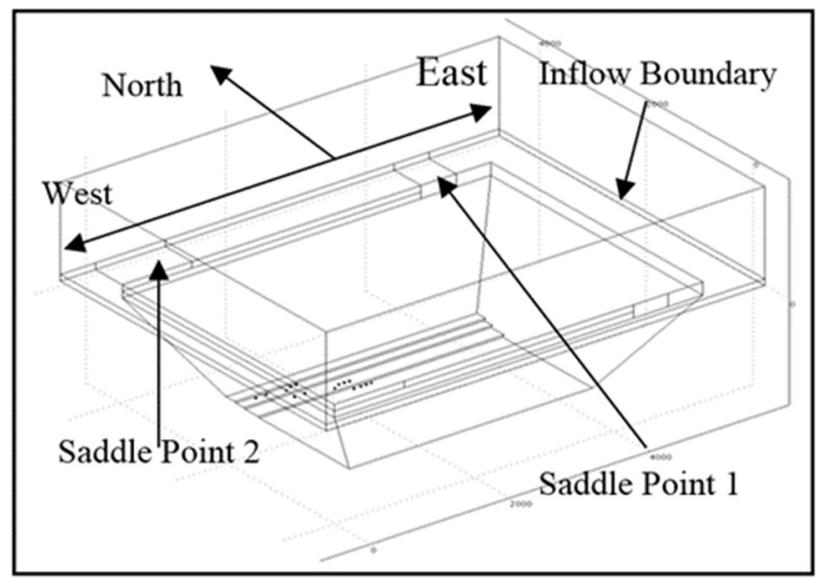

Figure 1: $3 \mathrm{D}$ validation model of the arctic mine.

The model is oriented in the east-west direction longitudinally. The pit is $5280 \mathrm{ft}$. $\times 3960 \mathrm{ft}$. at the rim. The depth of the pit is $1700 \mathrm{ft}$., and the height of the air envelope above the pit is $1500 \mathrm{ft}$. The two saddle points shown in Figure 7 represent two depressions or cuts in the pit rim, which may play a part in the ventilation of the deeper regions of the pit. Saddle Point 1 is the location where the haul road exits the pit, and Saddle Point 2 is the location of the active pushback area for new development.

The narrow atmospheric boundary at the east end of the mine is considered the inflow boundary through which low-velocity airflow is introduced. There is no other velocity inflow into the model space. The heat inflow into the model space is from two sources: (1) the reradiated heat from the mine surface (varies with time, i.e., sunrise and sunset), and (2) the heat from the equipment (constant through the model run time).

The model has been validated according to data collected during winter, at which time sunlight does not irradiate the deeper reaches of the mine. Consequently, only the horizontal surface at the rim of the pit participates actively in heat exchange. The remaining surfaces are programmed to conduct heat away from the model space at a very low rate. The horizontal surface, which participates actively in heat exchange with the mine air, is programmed to do so only during daylight hours, which, based on collected data, is approximately four hours each day.

The waste heat as well as the emissions from each kind of equipment is calculated according to Shah et al. [11]. The gases $\mathrm{NO}$ and $\mathrm{NO}_{2}$ are considered for the validation and sensitivity analysis of the model, because they have some of the lowest TLVs prescribed by the EPA. In addition, the arctic open pit in question has experienced high concentrations of these gases, resulting in shutdown of production.

The model was validated on three different days at three different locations. Validation was performed on the data from December 13, 2004, at Bench 1150. 
Since the location of the collected concentration data from the mine is not known, the peak model predicted value is considered from validation. The model was initiated about $13 \mathrm{hr} 15 \mathrm{~min}$ before the time at which validation was attempted and was executed for approximately $14 \mathrm{hr} 30 \mathrm{~min}$. The results obtained for both NO and $\mathrm{NO}_{2}$ are shown in Figures 2 and 3.

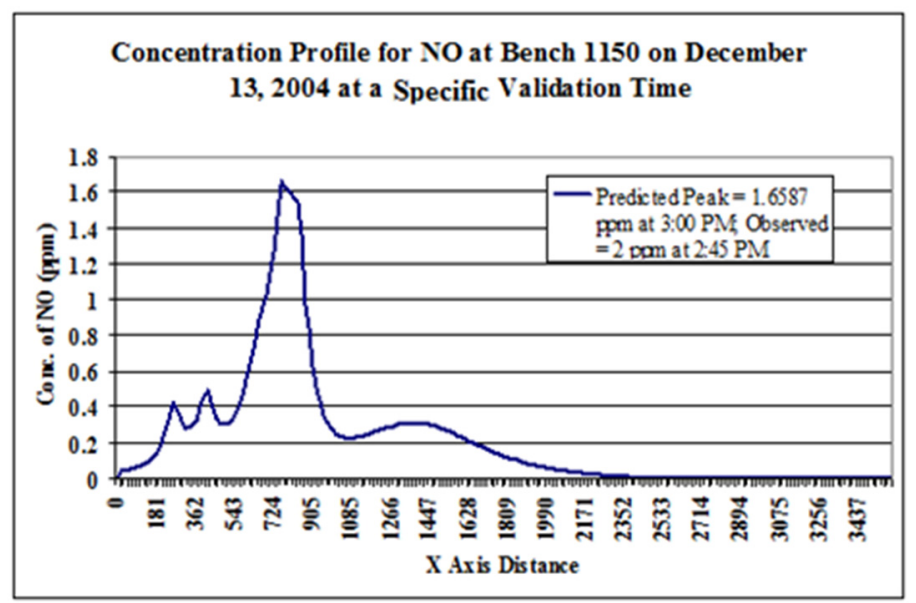

Figure 2: NO concentration profiles at validation time for Bench 1150 $(12 / 13 / 2004)$.

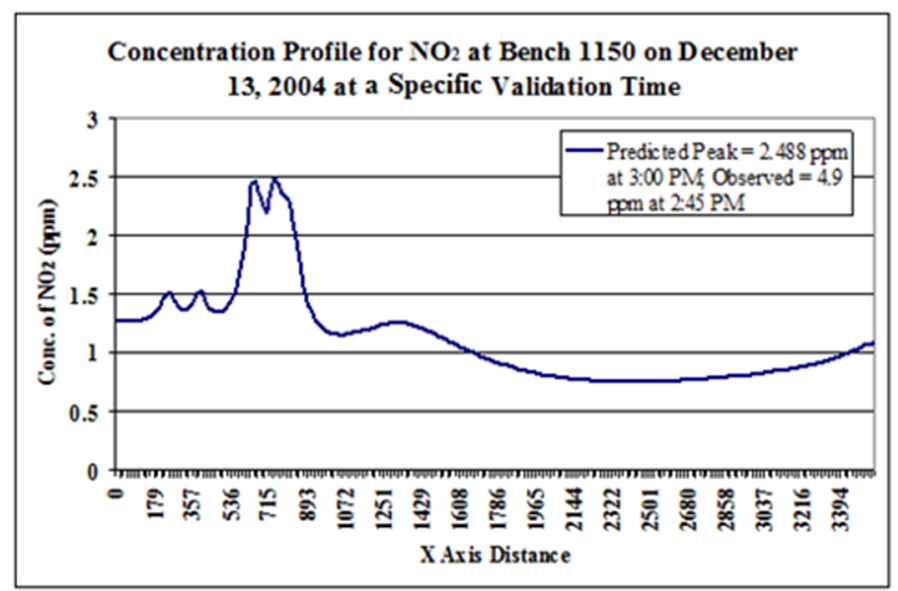

Figure 3: $\quad \mathrm{NO}_{2}$ concentration profiles at validation time for Bench 1150 $(12 / 13 / 2004)$.

As seen in Figures 2 and 3, the model is very closely validated for NO, and is validated for $\mathrm{NO}_{2}$ with a slightly larger error margin. 


\section{Effect of variable influent velocity on pollutant concentration profile}

The influent velocity is introduced directionally from the edge of the model pit. Airflow enters the model space and, upon interaction with the native air mass, initiates flow in the model space that carries the pollutants via advection. Some of the pollutants may be transported out of the mine space by this advective current. Thus, the stronger the current, the more pollutants may be transported out of the pit. The concentration of pollutants in the pit should decrease with increasing velocity. This hypothesis can be tested using several influent velocities in the model. The velocities used here were $2 \mathrm{ft} . / \mathrm{s}, 3 \mathrm{ft} . / \mathrm{s}$, and $5 \mathrm{ft} . / \mathrm{s}$. Concentration profiles were obtained in each case from the length of Bench 1150 in the horizontal direction, as well as in the vertical direction at the centre of the pit. The results obtained are shown in Figures 4 to 9.

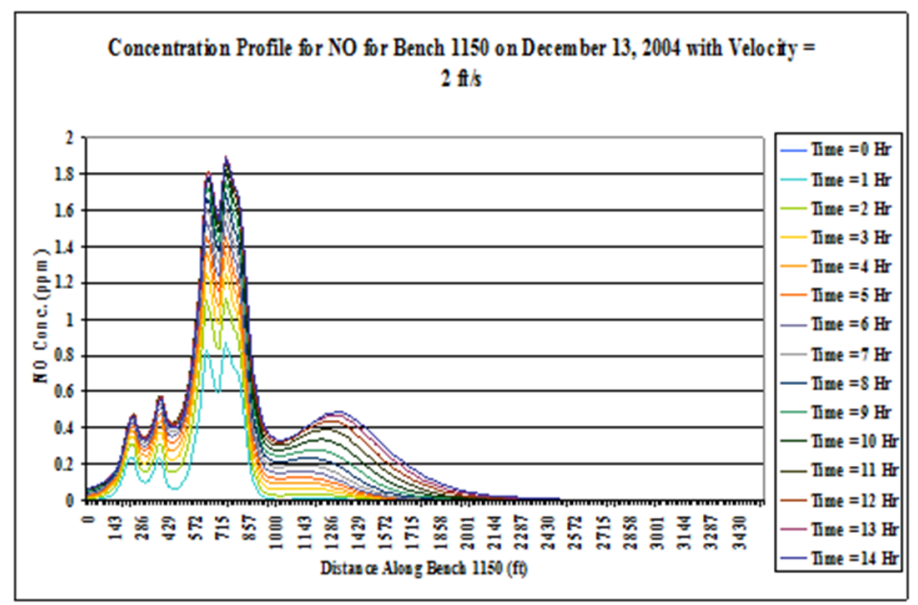

Figure 4: Concentration profile for NO along Bench 1150 (influent velocity $2 \mathrm{ft} . / \mathrm{s})$.

It can be seen from Figures 4 to 9 that an increase in velocity inflow partially mitigates pollutant concentrations in the open pit. Peak values for both locations decrease with increases in velocity. Note that while the shape of the profile along the longitudinal axis of Bench 1150 did not show significant changes for the range of velocities examined here, the profile is somewhat changed for the vertical axis at the midsection of the pit. For the lowest velocity of $2 \mathrm{ft} . / \mathrm{s}$ (Figure 4), maximum concentration can be observed at the pit bottom (approx. $0.0018 \mathrm{ppm}$, extreme left of the graph), after which the concentration steeply descends to zero near the inversion cap (extreme right of the graph). This trend continues for higher velocities ( $5 \mathrm{ft} . / \mathrm{s}$, Figure 9, peak value approx. $0.0005 \mathrm{ppm})$, where a further increase in intermediate values and further spreading of the "tight band" is noted. It appears that recirculation zones are formed where the pollutant is mixed, but the 


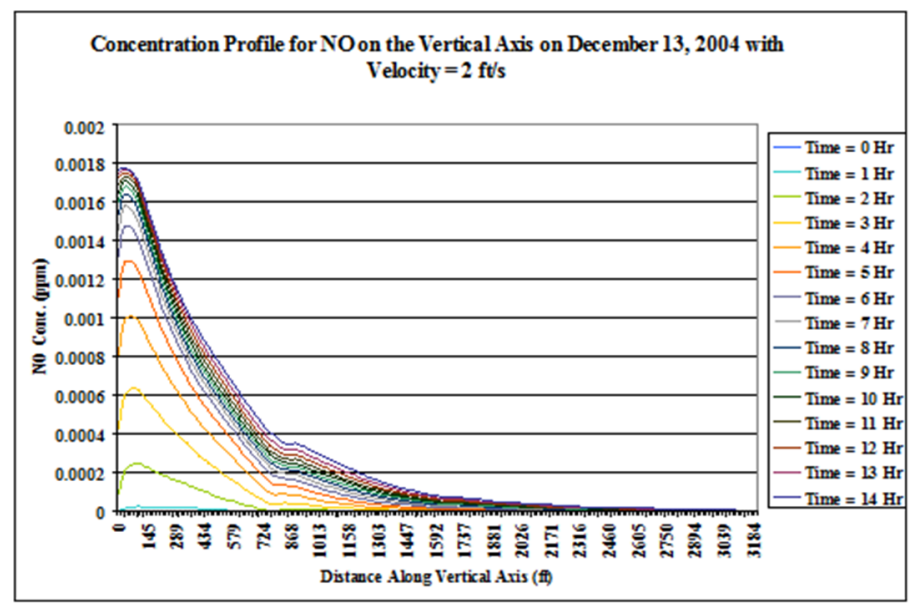

Figure 5: Concentration profile for NO along the vertical axis (influent velocity $2 \mathrm{ft} / \mathrm{s})$.

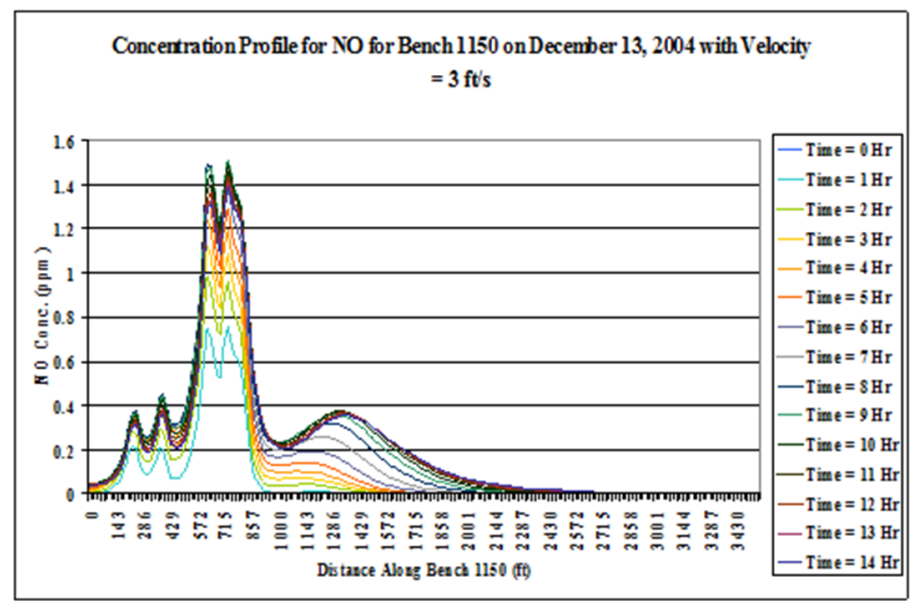

Figure 6: Concentration profile for NO along Bench 1150 (influent velocity $3 \mathrm{ft} . / \mathrm{s})$.

area of active circulation, the degree of opening, and the range of the vertical current are sharply decreased. The transport of pollutants out of the open pit, however, does not happen. This effect is a result of increased mixing and advection due to increasing velocity. It may be noted in Figures 5, 7, and 9 that there is a temporary, localized drop in concentration around an altitude of $750 \mathrm{ft}$. from the pit bottom. This small drop is due to the effect of vorticity and localized eddies that occurs there because of backflow in the air current. Similar effects were also evident in both the 2D and the 3D models. Such airflow is capable of transporting 
some of the pollutants away from the sources as well as the midsection of the pit, thus leading to a temporary though localized drop in concentration. In the three cases studied, flow pattern varied little, and its effect on pollution concentration was not substantial.

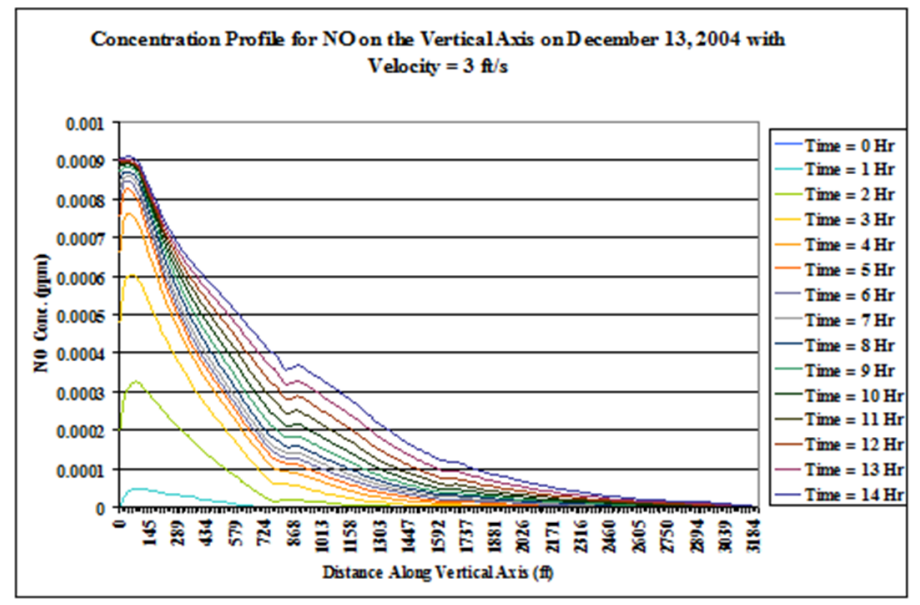

Figure 7: Concentration profile for NO along the vertical axis (influent velocity $3 \mathrm{ft} . / \mathrm{s})$.

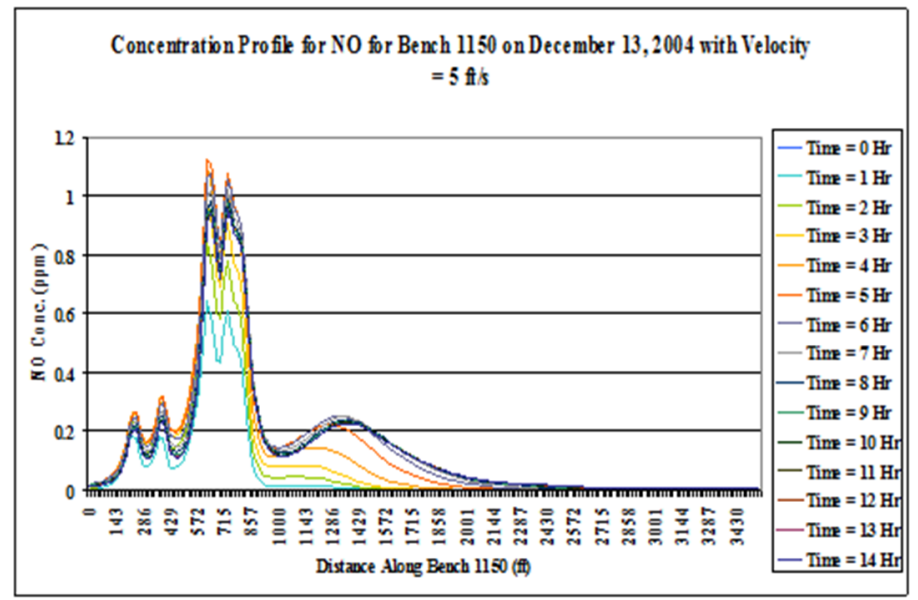

Figure 8: Concentration profile for NO along Bench 1150 (influent velocity $5 \mathrm{ft} . / \mathrm{s})$. 


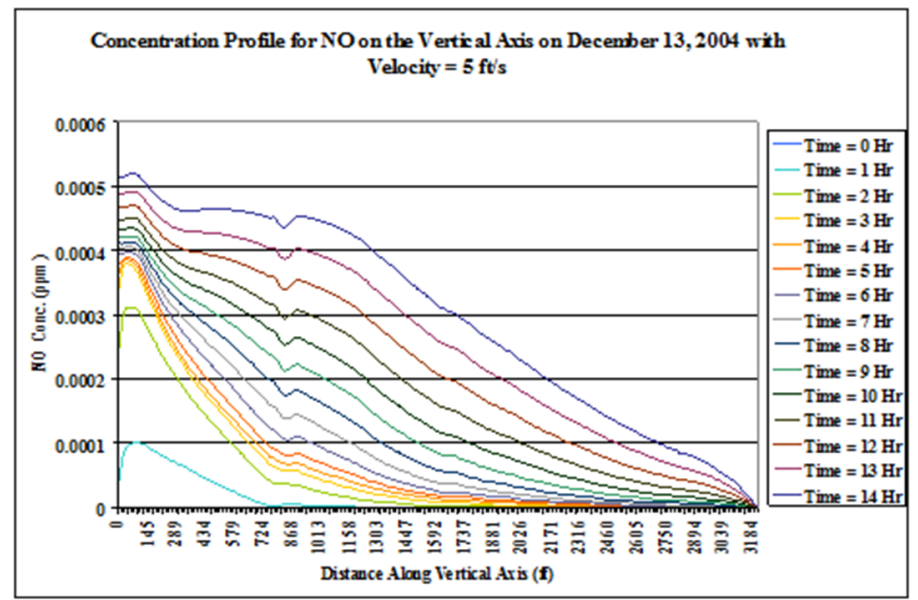

Figure 9: Concentration profile for $\mathrm{NO}$ along the vertical axis (influent velocity $5 \mathrm{ft} . / \mathrm{s})$.

Air velocity does not remain constant throughout a time period. It is often seen to increase uniformly to a peak value, and thereafter decay to its original time over time. This phenomenon, known as gust velocity, was also investigated in order to determine its effectiveness in removing contaminants from the pit. Gust velocities of $20 \mathrm{ft} . / \mathrm{s}, 30 \mathrm{ft} . / \mathrm{s}$ and $40 \mathrm{ft} . / \mathrm{s}$ were chosen. The results obtained were similar to the regular velocity analysis as presented before, with more eddy and turbulent mixing than before. For the sake of brevity, detailed results are not presented here.

\section{Conclusions}

Within limitations, both low influent air velocities and gust wind velocities are effective in removing gaseous pollutants from deep open-pit mines in the Arctic. The presence of an inversion cap on the pit often automatically reduces the influent air velocity, thus hindering pollutant removal. In the case of either low influent air or gust wind, increasing the magnitude of velocity does not result in monotonic reduction in pollutant concentration in the pit. However, in some cases, better mixing removes some pollutants from the pit bottom. In most of the modelled cases, the pollutants were not transported out of the pit, but were mixed or transported to the higher regions of the pit because of increased turbulence. It can be safely concluded that influent wind velocity cannot mitigate high concentrations of gaseous pollutants in open-pit mines in arctic and subarctic regions where there are air inversions. Other (artificial) measures to mitigate this potential environmental hazard are imperative. 


\section{References}

[1] Holty, J.G., Air Quality in a Sub-Arctic Community Fairbanks Alaska. Arctic, December, 26 (4), pp. 292-302, 1973.

[2] Hartmann, B. \& Wendler, G., Climatology of the Winter Surface Temperature Inversion in Fairbanks, Alaska. Geophysical Institute, University of Alaska, Fairbanks, AK 99775, 2005.

[3] Belousov, V.I., Breeze Circulation in Open Pit Mines. Journal of Mining Science, 31 (3), pp. 216-220, 1995.

[4] Belousov, V.I., Natural Dynamic Ventilation of Open Pit Mines. Soviet Mining Science, 21 (3), pp. 264-267, 1985.

[5] Belousov, V.I., Ventilation of Open Pit Mines by Controlling the Boundary Layer of the Wind Stream. Soviet Mining Science, 25 (3), pp. 267-270, 1989.

[6] Peng, X. and Lu, G.R., Physical Modelling of Natural Wind and Its Guide in Large Open Pit Mines. Journal of Wind Engineering and Industrial Aerodynamics, 54-55, pp. 473-481, 1995.

[7] Fomin, A.A., Modelling of Natural Convection in an Open Pit. Fluid Dynamics, 31 (4), pp. 490-496, 1996.

[8] Aloyan, A.E., Baklanov, A.A. \& Penenko, V.V., Fictitious Regions of Numerical Simulation of Quarry Ventilation. Meteorologiya i Gidrologiya, 7, pp. 42-49, 1982.

[9] Baklanov, A.A. \& Rigina, O. Yu. 1993, Effectiveness of Cascade Ventilation Systems for Open Pit Mines. Soviet Mining Science, pp.152157, 1993 (in Russian).

[10] Collingwood, W., Raj, K.V., Choudhury, A. \& Bandopadhyay, S., CFD modelling of airflow in an openpit mine. Mining Engineering, pp. 44-50, February 2012.

[11] Shah, S.D., Cocker, D.R. III, Johnson, K.C., Lee, J.M., Soriano, B.L. \& Miller, W., Emissions of Regulated Pollutants from In-Use Diesel Back-up Generator. Atmospheric Environment, 40, pp. 4199-4209, 2006. 